\title{
Effect of selenium, vitamins $E$ and $C$ on antioxidant potential and quality of boar ejaculate
}

\author{
P. Horky', J. Sochor ${ }^{24}$, J. Skladanka', I. Klusonova ${ }^{1}$ and P. Nevrkla ${ }^{3}$ \\ Mendel University in Brno, Faculty of Agronomy, ${ }^{1}$ Department of Animal Nutrition and Forage Production, \\ ${ }^{3}$ Department of Animal Breeding, Zemedelska 1, CZ-613 00 Brno, Czech Republic \\ ${ }^{2}$ Faculty of Horticulture, Department of Viticulture and Enology \\ Valticka 337, CZ-691 44 Lednice, Czech Republic
}

KEY WORDS: boars, ejaculate, sperm, selenium, vitamin $\mathrm{C}$, vitamin $\mathrm{E}$

Received: $\quad 16$ July 2015

Revised: 7 December 2015

Accepted: $\quad 7$ March 2016

\footnotetext{
${ }^{4}$ Corresponding author:

e-mail: sochor.jirik@seznam.cz
}

\begin{abstract}
The aim of the experiment was to examine the effect of dietary selenium, vitamins $C$ and $E$ mixture on the antioxidant status and quality of boar ejaculate (Duroc breed). For 90 days the boars were divided into two groups (7 in each group): experimental - fed diet supplemented with $\left(\mathrm{mg} \cdot \mathrm{kg}^{-1}\right.$ of diet) selenium 0.5 , vitamin C 350 and vitamin E 70; and control one. The ejaculate samples were collected during three periods: at the beginning (point zero), days $0-45$ and days $45-90$. The antioxidant status and ejaculate quality were assessed. A higher lipid peroxidation level in the ejaculate $(48 \% ; P<0.05)$ after 90 days was found in the control group. Also in this group decrease in sperm motility $(12 \% ; P<0.05)$ and increase in abnormal sperm percentage $(81 \% ; P<0.05)$ were observed in samples collected from days $45-90$. In comparison to point zero the antioxidant status of ejaculate increased in the experimental group when measured by ferric reducing antioxidant potential (85\%; $P<0.05)$ and 2,2,-dipheryl-1-picrylhydrazyl (130\%; $P<0.05)$ method and the lipid peroxidation decreased $(36 \% ; P<0.05)$ after 90 -day dietary treatment. The results observed in the samples collected from days $45-90$ showed that additional antioxidants mixture in the diet did not influence sperm quality; however did prevent from negative changes observed in the control group. In conclusion, the addition of selenium, mixture of vitamins $C$ and $E$ into diet increases the antioxidant status of ejaculate and keeps its quality on stable level.
\end{abstract}

\section{Introduction}

Selenium, vitamins $\mathrm{E}$ and $\mathrm{C}$ belong to the essential micronutrients in animal and human nutrition. Selenium is a component of glutathione peroxidase (GPx) reducing hydrogen peroxide to water (Goyal et al., 2013; Horký, 2015). Vitamin E acts against the peroxidation of polyene acids of biological membranes. Tocopherols exhibit the ability to donate a hydrogen atom by transferring it from the phenolic group to lipid free radicals thus stopping the chain reaction. The resulting phenoxyl radical may react with vitamin $C$, which is reduced by glutathione and coenzyme Q (Gao et al., 2014). It can also react with other free peroxyl radicals but, in this reaction, the irreversible oxidation of tocopherol can occur and the product can be expelled with the bile (Murer et al., 2014). Vitamin C is involved in the antioxidant protection of cells because of its reduction properties against tocopherol radical 
(An et al., 2014; Shapoval et al., 2003). Reactive oxygen forms can damage sperm compatibility and thus reduce their viability (Khosravi et al., 2014; Horký et al., 2012b). So the proper antioxidant system activity in the ejaculate plays an important role in keeping boars reproduction properties.

Superoxide dismutase (SOD) is an enzymatic component of the antioxidant defence system protecting spermatozoa by catalysing the dismutation of superoxide anions to hydrogen peroxide and oxygen. SOD activity is the highest in boars aged less than one year. Its highest activity was detected in the boar ejaculate in spring and autumn (Kowalowka et al., 2008; Orzołek et al., 2013). The other enzymes from antioxidant system which play an important role in boar ejaculate are: catalase (CAT), glutathione peroxidase (GPx), glutathione reductase (GR), glutathione transferase (GST) and phospholipid hydroperoxide glutathione peroxidase (PHGPx) (Koziorowska-Gilun et al., 2011; Horký, 2014). The antioxidants may improve ejaculate quality (Khosravi et al., 2014). The forms of reactive oxygen negatively affect the sperm quality and cause the lipid peroxidation (Ashrafi et al., 2013). Such forms of reactive oxygen in the ejaculate may also affect the metabolism of proteins (Jančíková et al., 2012a,b; Sharma et al., 2013). The antioxidants, secreted by the reproductive tract, may protect spermatozoa against the toxic effects of reactive oxygen species (ROS) after the ejaculation (Koziorowska-Gilun et al., 2011). The appropriate nutrition of pregnant sows and piglets should be followed after the suitable nutrition of boars. Otherwise, the breeding can become inefficient. These principles should be applied to all species of farm animals (Nevrkla et al., 2012, 2014). The aim of this experiment was to evaluate the influence of selenium, vitamin $\mathrm{E}$ and vitamin $\mathrm{C}$ supplementation on the antioxidant status and the quality of breeding boar ejaculate.

\section{Material and methods}

\section{Animals and animal care}

The experiment was carried out in the sperm collection centre of boars in Velke Mezirici (the Czech Republic). The experiment was conducted on 14 Duroc boars (devided into two groups of 7 animals) of the average age of $2 \pm 0.3$ years and the average weight of $250 \pm 20 \mathrm{~kg}$. The animals were housed individually $(2.5 \times 2.5 \mathrm{~m})$ with ad libitum access to water. All animals were fed by $3.3 \mathrm{~kg}$ of basic feed mixture (Table 1). The content of metabolizable energy (ME) was $12.6 \mathrm{MJ} \cdot \mathrm{kg}^{-1}$ diet. The basal diet
Table 1. Composition of basal diet fed to boars

\begin{tabular}{lc}
\hline Component & \% in feed mixture \\
\hline Barley grain & 36.00 \\
Wheat grain & 20.36 \\
Oat grain & 20.00 \\
Soyabean meal (SBM) & 14.50 \\
Biscuit meal $^{1}$ & 3.00 \\
Palm oil $^{2}$ & 2.10 \\
Calcium carbonate & 1.50 \\
Monodicalcium phosphate & 1.20 \\
Mineral-vitamin premix & 0.50 \\
Sodium chloride & 0.40 \\
Magnesium oxide & 0.15 \\
L-Lysine HCl & 0.14 \\
L-Threonine & 0.09 \\
DL-Methionine & 0.06 \\
\hline
\end{tabular}

${ }^{1}$ EKPO T (Delika - Pet, Lovčice, Czech Republic); ${ }^{2}$ Bergafat (Berg + Schmidt GmbH \& Co. KG, Hamburg, Germany); ${ }^{3}$ provided per kg of premix: IU: vit. A 3000000 , vit. $D_{3} 400000$; mg: vit. $B_{1} 500$, vit. $B_{2} 1200$, vit. $B_{6} 800$, vit. $B_{12} 6$, vit. $K_{3} 600$, biotin 70 , folic acid 200 , niacinamide 8000 , Ca pantothenate 4000 , choline chloride 55200 , betaine 26500 , butylhydroxi-toluene 400, ethoxyquin 180, Cu 2883 (as $\mathrm{CuSO}_{4} \cdot 5 \mathrm{H}_{2} \mathrm{O}$ ), $\mathrm{Zn} 19976$ (as $\mathrm{ZnO}$ ), Mg 19760 (as $\mathrm{MgO}$ ), $\mathrm{Fe} 23625$ (as $\mathrm{FeCO}_{3}$ ), $\mathrm{Co} 91$ (as $\mathrm{CoSO}_{4} \cdot 7 \mathrm{H}_{2} \mathrm{O}$ ); g: L-Lysine monohydrochloride 226 (Tekro, Prague, Czech Republic)

contained $0.02 \mathrm{mg}$ of selenium, $9.9 \mathrm{mg}$ of vitamin $\mathrm{E}$ and $16 \mathrm{mg}$ of vitamin $\mathrm{C}$ per $\mathrm{kg}$ of feed mixture. The control group was fed diet without additional selenium, vitamin $\mathrm{E}$ nor $\mathrm{C}$. The experimental group was fed diet with the addition of $0.5 \mathrm{mg}$ of selenium (selenomethionine; Alltech's, California, USA), $70 \mathrm{mg}$ of vitamin E (alpha-tocopherol; Tekro, Prague, Czech Republic) and $350 \mathrm{mg}$ of vitamin C (ascorbic acid; Tekro, Prague, Czech Republic) per $\mathrm{kg}$ of diet.

The premix was individually dosed to boars during the morning feeding. The content of selenium in the diet was determined by the atomic absorption spectrophotometry according to Lei and Marshall (1995). Vitamin E was determined by highperformance liquid chromatography (HPLC) according to Hosmanová and Douša (2007) and vitamin $\mathrm{C}$-according to the method of Rudenko and Kartasova (2010).

The experiment lasted 90 days during June, July and August in 2013. The boar ejaculate was collected once a week using the jump on the phantom technique. However, only the ejaculate samples taken at the beginning of the experiment (point zero), and on days 45 and 90 of the experiment were used for biochemical analyses. For determination of ejaculate volume, motility and the percentage of pathological sperms was performed once a week for each boar and the average was calculated for two timeintervals: from days $0-45$ and $45-90$, and compared to the point zero (Table 2). 
Table 2. Qualitative and quantitative values of boar ejaculate from control ${ }^{1}$ and experimental group ${ }^{2}$

\begin{tabular}{|c|c|c|c|c|c|c|}
\hline \multirow{2}{*}{$\begin{array}{l}\text { Indices } \\
\text { Time of samples collection, day }\end{array}$} & \multicolumn{3}{|c|}{ Control group $(n=7)$} & \multicolumn{3}{|c|}{ Experimental group $(n=7)$} \\
\hline & point zero & $0-45$ & $45-90$ & point zero & $0-45$ & $45-90$ \\
\hline No. of samples & 30 & 47 & 46 & 30 & 45 & 42 \\
\hline Ejaculate volume, $\mathrm{ml}$ & $203.3 \pm 27.1$ & $208.8 \pm 34.6$ & $220.9 \pm 25.3$ & $198.0 \pm 26.9$ & $199.6 \pm 23.3$ & $224.8 \pm 20.6$ \\
\hline Sperm concentration, thousand $/ \mathrm{mm}^{3}$ & $430.5 \pm 39.9$ & $433.2 \pm 32.3$ & $415.6 \pm 24.0$ & $499.1 \pm 31.1$ & $469.1 \pm 42.1$ & $454.3 \pm 48.5$ \\
\hline Sperm motility, \% & $70.9 \pm 1.7$ & $68.2 \pm 2.1$ & $62.5 \pm 1.8^{*}$ & $70.4 \pm 1.4$ & $70.9 \pm 1.1$ & $73.0 \pm 1.8$ \\
\hline Abnormal sperm, \% & $6.4 \pm 2.0$ & $7.4 \pm 1.7$ & $11.6 \pm 1.6^{*}$ & $6.2 \pm 1.3$ & $5.3 \pm 1.1$ & $5.0 \pm 1.5$ \\
\hline
\end{tabular}

${ }^{1}$ fed basal diet (see Table 1); ${ }^{2}$ fed basal diet with addition of Se $(0.5 \mathrm{mg})$, vitamin E $(70 \mathrm{mg})$ and C $(350 \mathrm{mg})$ per $\mathrm{kg}$ of diet; * - values significantly differnt from point zero in control group $(P<0.05)$

\section{Determination of ejaculate volume, sperm concentration and motility, and percentage of abnormal sperm}

The ejaculate and sperm parameters were determined according to the method of Lovercamp et al. (2013). The volume of semen was estimated by weighing each ejaculate and using the conversion: $1 \mathrm{~g}$ equals $1 \mathrm{ml}$ of semen. The sperm concentration was evaluated using a self-calibrating photometer $\left(\right.$ SpermaCue $\left.{ }^{\mathrm{TM}}\right)$. The motility analysis was performed using Sperm Vision ${ }^{\mathrm{TM}}$ software (both from Minitube of America, Verona, WI, USA) on images obtained by a digital camera attached to phase contrast microscope (Olympus IX 71 S8F-3; Tokyo, Japan). Prior to analysis, $500 \mu \mathrm{l}$ of each sample was diluted 1:1 with Androhep (Plemo, Hradec Králové, Czech Republic) extender and incubated at $37^{\circ} \mathrm{C}$ for $30 \mathrm{~min}$. The evaluation of sperm morphology and cellular particles was performed using a phase contrast microscope (Zeiss, Jena, Germany). The subjective analyses were always carried out by the same qualified person.

\section{Sample preparation for analyses}

Firstly, $0.5 \mathrm{ml}$ volume of native thawed ejaculate was pipetted followed by the addition of $2 \mathrm{ml}$ of liquid nitrogen and $0.5 \mathrm{ml}$ of phosphate buffer. Subsequently, the sample was homogenized for 2 min with the use of IKA Ultra-Turrax T8 homogenizer (IKA GmbH, Königswinter, Germany) set to $3000 \mathrm{rpm}$. Next, $1 \mathrm{ml}$ of phosphate buffer was added and sample was mixed for $15 \mathrm{~min}$ (Vortex-Genie 2; Scientific Industries Inc., NY, USA) with vortex set to $2000 \mathrm{rpm}$. Then the sample was centrifuged (Universal 32R centrifuge; Andreas Hettich GmbH \& Co. KG, Tuttlingen, Germany) at $16000 \mathrm{rpm}$ at $4{ }^{\circ} \mathrm{C}$ for $20 \mathrm{~min}$. The obtained supernatant was used for further analyses (except for measurement of ejaculate volume and sperm morphology).

\section{Determination of glutathione peroxidase activity}

Glutathione Peroxidase Cellular Activity Assay Kit (Cat. No. CGP1; Sigma-Aldrich, St. Louis, MO, USA) was used for the glutathione peroxidase activity (GPx) estimation in previously prepared ejaculate sample. Into a plastic cuvette $260 \mu$ of reagent R1 $(20 \times$ diluted NADPH Assay Reagent in GPx Assay Buffer that after dilution contained $0.25 \mathrm{mM}$ NADPH, $2.1 \mathrm{mM}$ reduced glutathione and 0.5 units $\cdot \mathrm{ml}^{-1}$ of glutathione recuctase; see Sigma technical bulletin) was pipetted with subsequent addition of $10 \mu \mathrm{l}$ of sample. Later, $30 \mu \mathrm{l}$ of reagent R2 (3 mM tert-Butyl hydroperoxide freshly prepared from $70 \%$ aqueous solution of tert-Butyl hydroperoxide by dilution in GPx Assay Buffer; see Sigma technical bulletin) was added to the reaction mixture. The enzymatic reaction has started. The decrease in absorbance was measured at $340 \mathrm{~nm}$ using kinetic programme for $126 \mathrm{~s}$ (BS 400 Chemistry Analyser; Mindray, Shenzhen, China). The results are listed in nkat $(\mathrm{U} \cdot \mathrm{ml} \times 16.6=\mathrm{nkat})$.

\section{Determination of superoxide dismutase activity}

A commercially available kit (Cat. No 19160; Sigma-Aldrich, St. Louis, MO, USA) was used for superoxide dismutase (SOD) activity assay. Firstly, $200 \mu \mathrm{l}$ of reagent R1 containing 20-time diluted WST-1 ((2-(4-Iodophenyl)- 3-(4-nitrophenyl)-5-(2,4disulfophenyl)-2H-tetrazolium, monosodium salt) solution was pipetted into a plastic cuvette and incubated in $37^{\circ} \mathrm{C}$ for $108 \mathrm{~s}$. Next, $20 \mu \mathrm{l}$ of prepared ejaculate sample was added. In $378 \mathrm{~s}$ the reaction was induced by $20 \mu 1$ reagent R2 (xanthine oxidase solution 167 times diluted with buffer) addition. The reaction mixture was incubated for $72 \mathrm{~s}$ and then the absorbance was measured at $450 \mathrm{~nm}$. Kinetic reaction was monitored for $180 \mathrm{~s}$ and the absorbance was measured at every $9 \mathrm{~s}$. The results are listed in nkat $(\mathrm{U} \cdot \mathrm{ml} \times 16.6=$ nkat $)$.

\section{Determination of antioxidant activity}

The total antioxidant activity of boar ejaculates was measured with the use of three methods: based on 2,2-azinobis (ABTS) radical, based on 2,2,-dipheryl-1-picrylhydrazyl (DPPH) radical and ferric reducing antioxidant potential (FRAP) method. 
The ABST method procedure was conducted according to Sochor et al. (2010): 7 mM2,2'-azinobis (3-ethyl-benzothiazoline-6-sulphonic acid, ABTS) solution and $4.95 \mathrm{mM}$ potassium peroxodisulphate were mixed to obtained $150 \mu 1$ of working solution to which $3 \mu$ l of prepared ejaculate sample was added. The absorbance was measured at $660 \mathrm{~nm}$ for $10 \mathrm{~min}$.

The FRAP method procedure was conducted according to Sochor et al. (2010): $150 \mu \mathrm{l}$ of freshly prepared FRAP working solution (containing TPTZ (2,4,6-tripyridyl-s-triazine) and $\mathrm{FeCl}_{3}$ ) was injected into a plastic cuvette with subsequent addition of a $3 \mu \mathrm{l}$ of sample. The absorbance was measured at $605 \mathrm{~nm}$ for $10 \mathrm{~min}$.

The procedure of DPPH test was conducted according to Pohanka et al. (2012): $150 \mu 1$ of reagent containing $0.095 \mathrm{mM}$ 2,2-diphenyl-1-picrylhydrazyl radical (DPPH) was incubated with $15 \mu 1$ of prepared ejaculate sample. The absorbance was measured at $505 \mathrm{~nm}$ for $10 \mathrm{~min}$.

The results of antioxidant activity obtained by ABST, FRAP and DPPH methods were calculated on the basis of the standard curve prepared using gallic acid (GAE) expressed as $\mathrm{mg} \cdot 1^{-1}$.

\section{Determination of ejaculate selenium concentration}

The concentration of selenium was determined using differential pulse voltammetry by 797 VAComputrace and 889 IC Sample Center (Metrohm, Switzerland) using a standard cell with three electrodes. The hanging mercury drop electrode (HMDE) with a drop area of $0.4 \mathrm{~mm}^{2}$ was used for the working electrode. The $\mathrm{Ag} / \mathrm{AgCl} / 3 \mathrm{M} \mathrm{KCl}$ electrode was the reference one and the glassy carbon electrode was the auxiliary electrode. The analysed ejaculate samples were deoxygenated prior to the measurements by purging with argon $(99.999 \%)$ and saturated with water for $120 \mathrm{~s}$. The measurement parameters were as follows: deposition potential $-0.6 \mathrm{~V}$, accumulation time for $200 \mathrm{~s}$, pulse amplitude $0.03 \mathrm{~V}$, pulse time for $0.05 \mathrm{~s}$, voltage step $0.006 \mathrm{~V}$, voltage step time for $0.1 \mathrm{~s}$, sweep rate $0.06 \mathrm{~V} \cdot \mathrm{s}^{-1}$, equilibration time for $30 \mathrm{~s}$. Total volume of the measuring vessel was $2 \mathrm{ml}(1980 \mu \mathrm{l}$ of electrolyte and $20 \mu \mathrm{l}$ of sample). The electrolyte for selenium was prepared by using $0.015 \mathrm{mM}$ ammonium sulphate with the addition of copper sulphate (the final concentration of $\mathrm{CuSO}_{4}$ was $0.05 \mathrm{mM}$ ). The $\mathrm{pH}$ of this electrolyte was adjusted to 2.2 using sulphuric acid. The scan was in the range of potentials from $-0.4 \mathrm{~V}$ to $-0.9 \mathrm{~V}$ and the characteristic peak of selenium was recorded at potential of $-0.7 \mathrm{~V}$.

\section{Photometric determination of malondialdehyde}

The principle of malondialdehyde (MDA) determination is the reaction between MDA and thiobarbituric acid (TBA) under the formation of TBA-MDA-TBA adduct strongly absorbing at $535 \mathrm{~nm}$. Trichloroacetic acid (TCA) is added to the sample because of its ability to precipitate proteins, bilirubin, unsaturated fatty acids and lipoproteins. Prepared ejaculate sample in the amount of $300 \mu 1$ was mixed with $10 \mu 1$ of $0.5 \mathrm{M}$ solution of butylated hydroxytoluene (BHT) in $96 \%$ ethanol (v/v) and $310 \mu \mathrm{l}$ of $20 \% \mathrm{TCA}(\mathrm{v} / \mathrm{v})$ prepared in $0.6 \mathrm{M} \mathrm{HCl}$. After 20 min of incubation on ice, mixture was centrifuged at $11000 \mathrm{rpm}$ for $15 \mathrm{~min}$. Subsequently, $400 \mu \mathrm{l}$ of supernatant was mixed with $800 \mu 1$ of $30 \mathrm{mM}$ TBA and the mixture was incubated in a Thermomixer Comfort (Eppendorf, Hamburg, Germany) at $90^{\circ} \mathrm{C}$ for $30 \mathrm{~min}$. After cooling in ice, the absorbance for MDA was measured using a spectrophotometer set at $535 \mathrm{~nm}$ and the concentration was subtracted from the calibration curve. The results are listed in $\mu \mathrm{mol} \cdot 1^{-1}$.

\section{Statistical analysis}

The data was processed statistically using STATISTICA.CZ, ver. 10.0 (2010) (StatSoft Inc., Tulsa, OK, USA). The obtained results were expressed as mean \pm standard deviation (SD). Statistical significance was determined by the examination of the basic differences between the individual samples using ANOVA and Scheffe's method (two-factor analysis). The first sampling, conducted before the start of the experiment, was considered as a point zero. The differences with $P<0.05$ were found significant.

\section{Results}

The obtained results showed that in the control group the antioxidant activity of boar ejaculate did not change during the whole experiment regardless of the method of measurement used. The total antioxidant activity potential measured by FRAP method (Figure 1A) increased in the experimental group by $55 \%(P<0.05)$ in samples collected on day 45 and by $85 \%(P<0.05)$ in samples collected on day 90 in comparison to point zero. According to the results obtained for 2,2,-dipheryl-1-picrylhydrazyl (DPPH) method (Figure 1B), the antioxidant activity of boar ejaculate was increased by $130 \%(P<0.05)$ in the samples collected on day 90 in comparison to point zero. There was no difference in the value of antioxidant activity measured by 2,2-azinobis (ABTS) in the experimental group. 

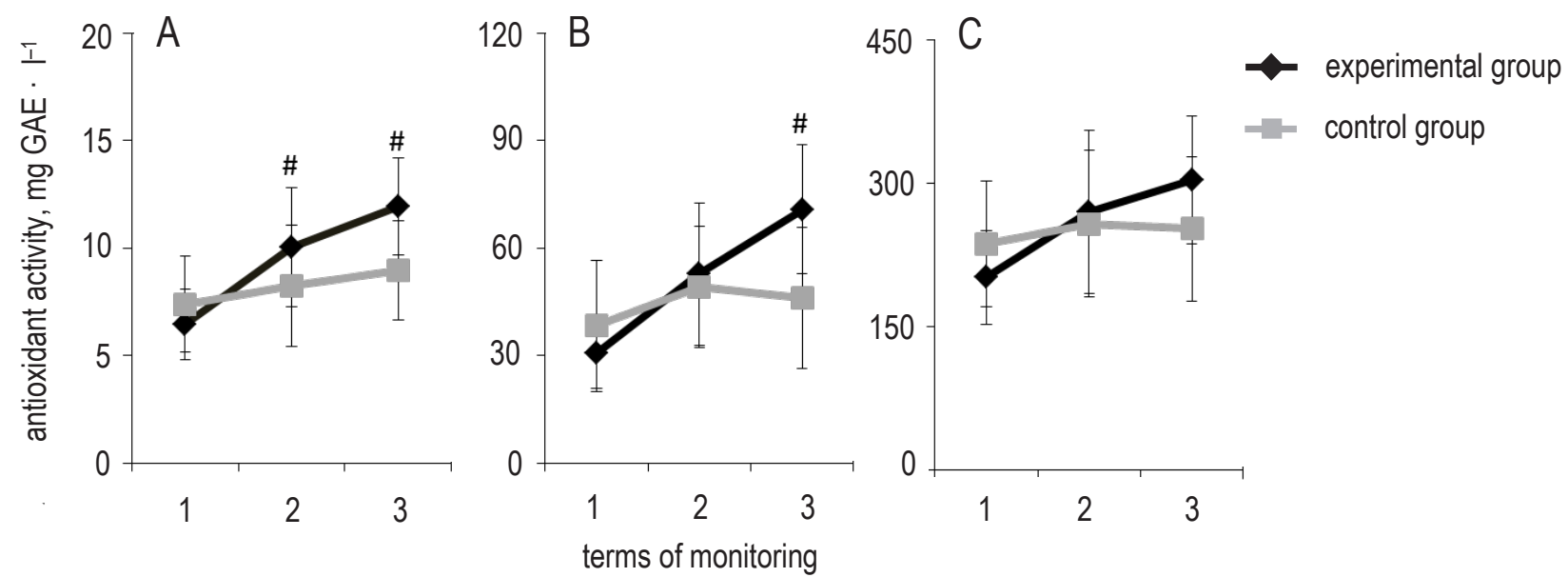

Figure 1. Antioxidant activity of boar ejaculates determined by ferric reducing antioxidant potential (FRAP) (A), 2,2,-dipheryl-1-picrylhydrazyl (DPPH) (B) and 2,2-azinobis (ABTS) (C) methods. Values are expressed in gallic acid (GAE), $\mathrm{mg} \cdot \mathrm{l}^{-1}$; \# - indicates values significantly differnt from point zero for experimental group $(P<0.05)$; term of monitoring: 1 - point zero; 2 - day 45,3 - day 90
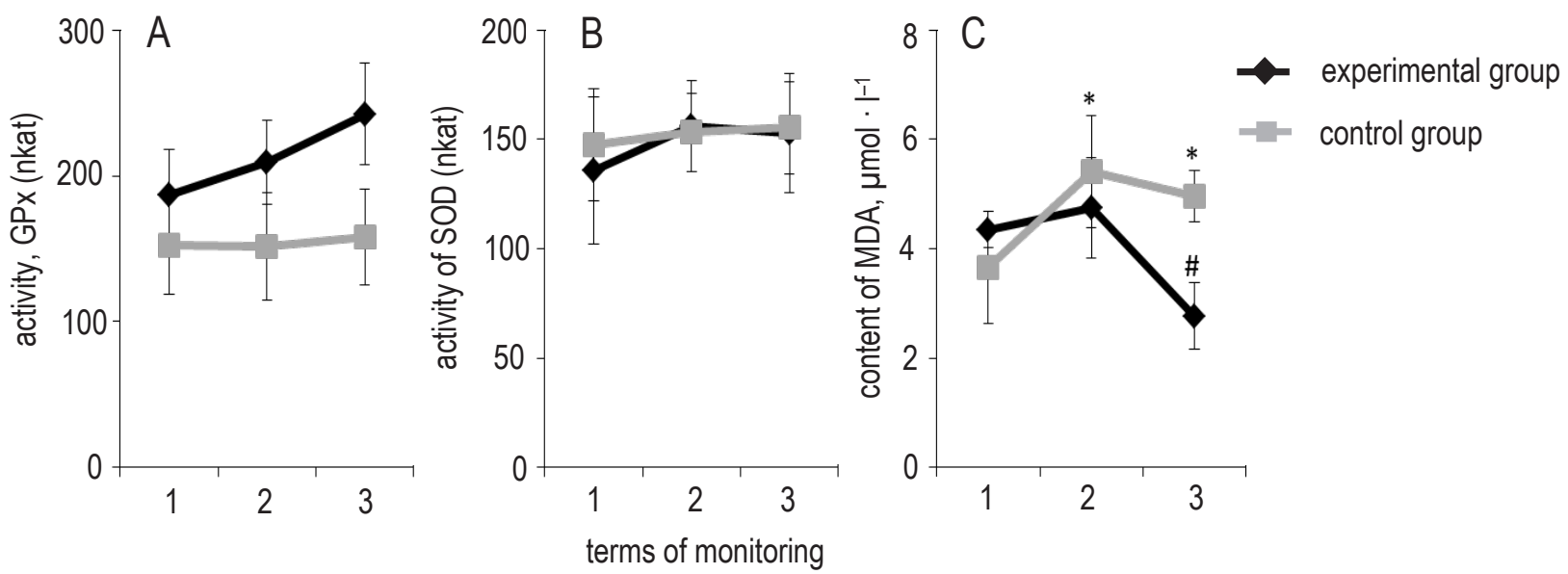

Figure 2. Changes in antioxidative enzymes activity (glutathione peroxidase (GPx; A), sodium dismutase (SOD; B)) and lipid peroxidation level (measured as content of malondialdehyde $(\mathrm{MDA} ; C)$ ) in boar ejaculate; * - values significantly differnt from point zero for control group $(P<0.05)$; \# - values significantly differnt from point zero for experimental group $(P<0.05)$; terms of monitoring: 1 - point zero; 2 - day 45,3 - day 90

The glutathione peroxidase (GPx) activity in boar ejaculate did not differ between each measurement point for either control and experimental group (Figure 2A). The superoxide dismutase (SOD) activity (Figure 2B) did not differ between measurement points for either control or experimental group.

Lipid peroxidation level (Figure 2C), measured by malondialdehyde (MDA) content in boar ejaculate, was significantly increased in the control group by about 48 and $36 \%(P<0.05)$ in samples collected on day 45 and 90 , respectively, in comparison to point zero. In the experimental group the lipid peroxidation level was significantly lower by $36 \%$ $(P<0.05)$ in samples collected on day 90 in comparison to corresponding point zero.

Selenium concentration in the boar ejaculate (Figure 3) did not change during experiment neither in control nor in experimental group.

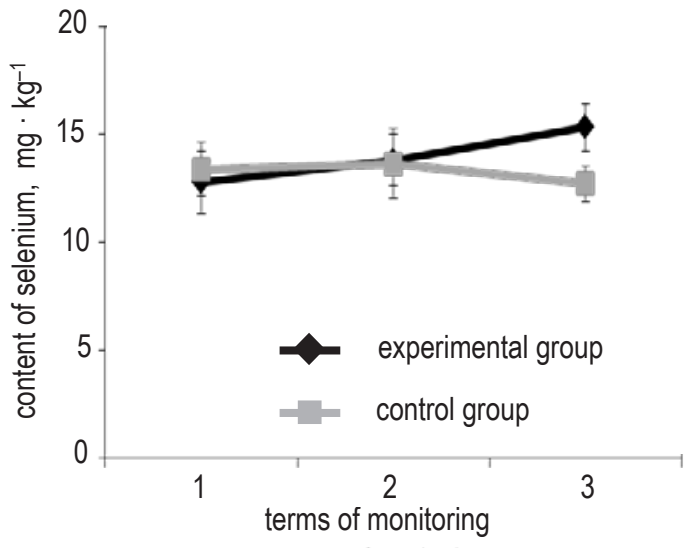

Figure 3. Selenium concentration in ejaculate; terms of monitoring: 1 - point zero; 2 - day 45,3 - day 90 
The evaluation of semen quantity and quality is presented in Table 2. The obtained results showed that in both control and experimental group the boar ejaculate volume and sperm concentration did not change during the whole experiment. In the control group the sperm motility was significantly decreased $(12 \%, P<0.05)$ in the samples collected from days $45-90$. In the experimental group no difference was observed during the experiment. The percentage of abnormal sperm was increased $(81 \%, P<0.05)$ in the samples collected from days $45-90$ in comparison to point zero for control group. In the experimental group no difference in examined parameter was observed during the whole experiment.

\section{Discussion}

In the presented study the total antioxidant activity of boar ejaculate was determined using ferric reducing antioxidant potential (FRAP), 2,2-azinobis (ABTS) and 2,2,-dipheryl-1-picrylhydrazyl (DPPH) tests. The activity of antioxidant system enzymes, such as glutathione peroxidase (GPx) and superoxide dismutase (SOD), and lipid peroxidation level was also measured. These markers were selected on the basis of the direct relationship between them and the intake of the antioxidants (selenium, vitamins $\mathrm{E}$ and C). The antioxidant activity is the indicator of the antioxidants total content in the sample. It is a marker assessing the ability of the whole body/selected organ to prevent from free radicals formation or to convert them into less reactive forms. Reduced antioxidant activity leads to intensified oxidative stress which is linked to whole body fatigue, low performance and diseases progression.

The disturbances in the functioning of the antioxidant system may be expressed by an increased degree of lipid peroxidation. In the present study the lipid peroxidation level measured by malondialdehyde (MDA) content in boar ejaculate was significantly increased in the control group and significantly decreased in group fed diet with additional antioxidants mixture. Also López et al. (2010) observed lower levels of MDA and higher levels of GPx activity when selenium $(0.4 \mathrm{mg}$ of Se per $\mathrm{kg}$ of diet) was added to the diet. The positive influence of additional dietary vitamin E (400 mg) on MDA reduction in the boar ejaculate was also stated by Liu et al. (2015), who also observed increased SOD activity after vitamin E supplementation.

The decreased lipid peroxidation level in the diet caused by addition of extra doses of antioxidants can be connected with increased overall antioxidant capacity of the ejaculate. In another experi- ment by Horký et al. (2012a) carried out on breeding boars, the significant increase of the ejaculate antioxidant status measured by FRAP and ABTS tests was found when additional dose $\left(0.6 \mathrm{mg} \cdot \mathrm{kg}^{-1}\right.$ diet $)$ of selenium in the organic form was added. The researchers also observed the increased activity of GPx and SOD, and selenium concentration in the ejaculate. Such observation are partially in common with the results observed in this experiment in which FRAP and DPPH tests indicated increased total antioxidant capacity but SOD activity did not changed. Also GPx and selenium content did not changed in experimental group throughout the whole experiment. In another experiment, the effect of organic forms of selenium $\left(0.5 \mathrm{mg} \cdot \mathrm{kg}^{-1}\right.$ diet $)$ on the antioxidant status of sow body after birth was estimated by Horky et al. (2013). In this experiment, the significant increase of antioxidant activity measured by FRAP, ABTS and free radicals (FR) method as well as the increase of selenium concentration in erythrocytes were found. Comparing results of the present experiment to the one conducted by Horky et al. (2013) it can be stated that observed increase of antioxidant activity was not so high. This result can be explained by the fact that the present experiment was conducted in the summer when the boars could have been exposed to a heat stress.

The relationship between the antioxidant capacity of ejaculate and semen quality was stated by Pahune et al. (2013). They observed that the ejaculate, which was characterized as substandard one, showed greatly reduced antioxidant capacity measured by FRAP method. In the present experiment, FRAP as well as DPPH values were found lower in the control group of boars which was also characterized with the reduced sperm motility and the increased percentage of abnormal sperm. However this negative effect was avoided when the mixture of examined antioxidants was added to the diet. The positive effect of the supplementation of vitamins $\mathrm{C}$ and $\mathrm{E}$ on sperm motility and viability was observed by Audet et al. (2004); however ejaculate volume and sperm concentration were not affected. The higher sperm motility was also observed by López et al. (2010) who examined the influence of selenium supplementation on boar ejaculate quality. They also observed that addition of $0.4 \mathrm{mg}$ of Se per $\mathrm{kg}$ of diet significantly increased the concentration of selenium in the ejaculate. Also Thongchalam et al. (2012) observed the increased concentration of selenium in ejaculates after adddition of $0.15 \mathrm{mg}$ Se per $\mathrm{kg}$ to boar diet. Also the results obtained in the present study showed that selenium concentration in the boar ejaculate 
was higher in the experimental group in comparison to control group after the 90-day feeding period. Also Speight et al. (2012) observed the increased sperm motility after addition of $0.3 \mathrm{mg}$ of Se to the diet. Moreover, it was estimated that vitamin E also positively affectes sperm quality reducing the percentage of the abnormal sperm at the dose of 300 and $450 \mathrm{mg} \cdot \mathrm{kg}^{-1}$ (Moraes et al., 2010; Xia et al., 2012). Simultaneously Xia et al. (2012) found that a higher content of antioxidants in the ejaculate improves sperm motility and increases the ability of sow gestation.

However, the beneficial effect of antioxidants on sperm quality is not widely confirmed. The Lovercamp et al. (2013) stated that neither organic nor inorganic selenium addition at the dose $0.3 \mathrm{mg}$ Se per $\mathrm{kg}$ of diet exerted influence on the sperm quality (volume, concentration, motility, morphology) as well as on the antioxidant capacity (lipid peroxidation, activity of GPx). Such results, however, remain in contradiction with the results observed in the present study, but it must be remembered that in this experiment the influence of three different antioxidants mixture (selenium, vitamins $\mathrm{C}$ and $\mathrm{E}$ ) was examined so their positive influence could be intensified.

\section{Conclusions}

The mixture of selected antioxidants (selenium, vitamins $\mathrm{E}$ and $\mathrm{C}$ ) added to boar diet prevents from the intensified lipid peroxidation in ejaculate and increases sperm antioxidant capacity. Moreover, such mixture addition keeps the ejaculate quality on the stable level avoiding an increase of abnormal sperm percentage and a decrease in sperm motility.

\section{Acknowledgement}

The project was funded by Grant No. IGA TP 2/2015 'Effect of selenium on the quality of plant and animal production from the perspective of health safety'.

\section{References}

An L., Li Z., Zhang T., 2014. Reversible effects of vitamins C and $\mathrm{E}$ combination on oxidative stress-induced apoptosis in melamine-treated PC12 cells. Free Radical Res. 48, 239-250

Ashrafi I., Kohram H., Ardabili F.F., 2013. Antioxidative effects of melatonin on kinetics, microscopic and oxidative parameter of cryopreserved bull spermatozoa. Anim. Reprod. Sci. 139, 25-30

Audet I., Laforest J.P., Martineau G.P., Matte J.J., 2004. Effect of vitamin supplements on some aspects of performance, vitamin status, and semen quality in boars. J. Anim. Sci. 82, 626-633
Gao J., Koshio S., Ishikawa M., Yokoyama S., Mamauag R.E.P., 2014. Interactive effects of vitamin $C$ and $E$ supplementation on growth performance, fatty acid composition and reduction of oxidative stress in juvenile Japanese flounder Paralichthys olivaceus fed dietary oxidized fish oil. Aquaculture 422-423, 84-90

Goyal A., Terry M.B., Siegel A.B., 2013. Serum antioxidant nutrients, vitamin A, and mortality in U.S. adults. Cancer Epidem. Biomarker. Prev. 22, 2202-2211

Horký P., 2014. Influence of increased dietary selenium on glutathione peroxidase activity and glutathione concentration in erythrocytes of lactating sows. Ann. Anim. Sci. 14, 869-882

Horkỳ P., 2015. Effect of selenium on its content in milk and performance of dairy cows in ecological farming. Potravinarstvo 9 , 324-329

Horky P., Jancikova P., Sochor J. et al., 2012a. Effect of organic and inorganic form of selenium on antioxidant status of breeding boars ejaculate revealed by electrochemistry. Int. J. Electrochem. Sci. 7, 9643-9657

Horký P., Jančíková P., Zeman L., 2012b. The effect of a supplement of chromium (picolinate) on the level of blood glucose, insulin activity and changes in laboratory evaluation of the ejaculate of breeding boars. Acta Univ. Agric. Silvic. Mendelianae Brun. $60,49-56$

Horky P., Ruttkay-Nedecky B., Kremplova M. et al., 2013. Effect of different doses of organically bound selenium on antioxidant status and levels of metal ions in postpartum sows. Int. J. Electrochem. Sci. 8, 6162-6179

Hosmanová R., Douša M., 2007. HPLC determination of vitamin E in feed materials, compounded feeds and foods. Chem. Listy 101, 578-583

Jančíková P., Horký P., Zeman L., 2012a. The effect of feed additive containing vitamins and trace elements on the elements profile and growth of skin derivatives in horses. Ann. Anim. Sci. 12, 381-391

Jančíková P., Horký P., Zeman L., 2012b. The effect of various copper sources on the trace elements profile in the hair, plasma and feaces and copper aktivity in the organism of horses. Acta Univ. Agric. Silvic. Mendelianae Brun. 60, 145-151

Khosravi F., Valojerdi M.R., Amanlou M., Karimian L., Abolhassani F., 2014. Relationship of seminal reactive nitrogen and oxygen species and total antioxidant capacity with sperm DNA fragmentation in infertile couples with normal and abnormal sperm parameters. Andrologia 46, 17-23

Koziorowska-Gilun M., Koziorowski M., Fraser L., Strzeżek J., 2011. Antioxidant defence system of boar cauda epididymidal spermatozoa and reproductive tract fluids. Reprod. Domest. Anim. $46,527-533$

Kowalowka M., Wysocki, P., Fraser L., Strzezek J., 2008. Extracellular superoxide dismutase of boar seminal plasma. Reprod. Domest. Anim. 43, 490-496

Lei T., Marshall W.D., 1995. Selenium speciation by high-performance liquid chromatography with online detection by atomicabsorption spectrometry. Appl. Organomet. Chem. 9, 149-158

Liu Q., Zhou Y.F., Duan R.J., Wei H.K., Jiang S.W., Peng J., 2015. Effects of dietary n-6:n-3 fatty acid ratio and vitamin $E$ on semen quality, fatty acid composition and antioxidant status in boars. Anim. Reprod. Sci. 162, 11-19

Lovercamp K.W., Stewart K.R., Lin X., Flowers W.L., 2013. Effect of dietary selenium on boar sperm quality. Anim. Reprod. Sci. 138, 268-275

López A., Rijsselaere T., Van Soom A., Leroy J.L.M.R., De Clercq J.B.P., Bols P.E.J., Maes D., 2010. Effect of organic selenium in the diet on sperm quality of boars. Reprod. Domest. Anim. 45, e297-e305 
Moraes E.A., Torres C.A.A., Guimarães J.D., Murgas L.D.S., 2010. Effect of oil sources and vitamin $E$ supplementation in the diet on physical and morphological characteristics of fresh boar semen. Arq. Bras. Med. Vet. Zootec. 3, 521-527

Murer S.B., Aeberli I., Braegger C.P., Gittermann M., Hersberger M., Leonard S.W., Taylor A.W., Traber M.G., Zimmermann M.B., 2014. Antioxidant supplements reduced oxidative stress and stabilized liver function tests but did not reduce inflammation in randomized controlled trial in obese children and adolescents. J. Nutr. 144, 193-201

Nevrkla P., Čechová M., Hadaš Z., 2012. Analysis of piglet losses in farrowing houses with different technologies. Acta Univ. Agric. Silvic. Mendelianae Brun. 60, 267-274

Nevrkla P., Čechová M., Hadaš Z., 2014. Use of repopulation for optimizing sow reproductive performance and piglet loss. Acta Vet. Brno 83, 321-325

Orzołek A., Wysocki P., Strzeżek J., Kordan W., 2013. Superoxide dismutase (SOD) in boar spermatozoa: purification, biochemical properties and changes in activity during semen storage $\left(16^{\circ} \mathrm{C}\right)$ in different extenders. Reprod. Biol. 13, 34-40

Pahune P.P., Choudhari A.R., Muley P.A., 2013. The total antioxidant power of semen and its correlation with the fertility potential of human male subjects. J. Clin. Diagn. Res. 7, 991-995

Pohanka M., Sochor J., Ruttkay-Nedecký B., Cernei N., Adam V., Hubálek J., Stiborová M., Eckschlager T., Kizek R., 2012. Automated assay of the potency of natural antioxidants using pipetting robot and spectrophotometry. J. Appl. Biomed. 10, 155-167
Rudenko A.O., Kartsova L.A., 2010. Determination of water-soluble vitamin $B$ and vitamin $C$ in combined feed, premixes, and biologically active supplements by reversed-phase HPLC. J. Anal. Chem. 65, 71-76

Shapoval G.S., Gromovaia V.F., 2003. Mechanism of antioxidant protection of an organism from oxidative stress (in Russian). Ukr. Biokhim. Zh. (1999) 75, 5-13

Sharma R., Agarwal A., Mohanty G., Du Plessis S.S., Gopalan B., Willard B., Yadav S.P., Sabanegh E., 2013. Proteomic analysis of seminal fluid from men exhibiting oxidative stress. Reprod. Biol. Endocrinol. 11, 85, doi: 10.1186/1477-7827-11-85

Sochor J., Salaš P., Zehnálek J., Krška B., Adam V., Havel L., Kizek R., 2010. An assay for spectrometric determination of antioxidant activity of a biological extract (in Czech). Listy Cukrov. 126, 416-417

Speight S.M., Estienne M.J., Harper A.F., Crawford R.J., Knight J.W., Whitaker B.D., 2012. Effects of dietary supplementation with an organic source of selenium on characteristics of semen quality and in vitro fertility in boars. J. Anim. Sci. 90, 761-770

Thongchalam K., Rukkwamsuk T., Chomchai S., 2012. Blood and semen selenium concentrations and semen quality in boars fed diets supplemented with organic or inorganic selenium. J. Anim. Vet. Adv. 11, 603-608

Xia C., Xia W., Yang S., An L., Li X., Wu Z., Zhang J., Wang Z., Tian J.H., 2012. Effect of antioxidant supplementation on function and fertility of sex-sorted boar spermatozoa. Anim. Reprod. Sci. $136,108-114$ 